\title{
MODEL MANAJEMEN KUALITAS MBNQA DALAM MENINGKATKAN DAYA SAING PRODUK UKM DI KABUPATEN SIDOARJO
}

\author{
${ }^{1}$ Billy Yhovizmiaji, ${ }^{2}$ Wiwik Sulistiyowati \\ ${ }^{1,2}$ Program Studi Teknik Industri, Universitas Muhammadiyah Sidoarjo, \\ Jalan Raya Gelam No. 250, Gelam, Candi, Sidoarjo \\ e-mail: billyyhovizmiaji@gmail.com
}

\begin{abstract}
Abstrak
UKM (Usaha Kecil Menengah) adalah Kegiatan ekonomi rakyat yang berskala kecil dengan bidang usaha yang secara mayoritas merupakan kegiatan usaha kecil dan perlu dilindungi untuk mencegah dari persaingan usaha yang tidak sehat. Untuk itu diperlukan manajemen kualitas pada UKM (Usaha Kecil Menengah) untuk meningkatkan daya saing produk yang akan dijual.Metode yang digunakan adalah Malcolm Baldridge National Quality Award (MBNQA) yang digunakan untuk menentukan indikatorindikator yang mempengaruhi daya saing produk. Metode tersebut diintegrasikan dengan Structural Equation Modeling (SEM) untuk mengetahui indikator yang terpenting dalam meningkatkan daya saing produk. Hasil dalam penelitian ini telah menunjukkan bahwa kepemimpinan, perencanaan strategi, pengukuran analisa dan manajemen pengetahuan, fokus sumber daya manusia, dan manajemen proses berpengaruh terhadap daya saing produk UKM (Usaha Kecil Menengah) dan semoga hasil penelitian ini bisa memberikan informasi bagi penulis, dan para pelaku UKM (Usaha Kecil Menengah) di Kabupaten Sidoarjo.
\end{abstract}

Kata kunci : UKM, Manajemen Kualitas, MBNQA, SEM

\section{PENDAHULUAN}

Usaha Kecil Menengah merupakan sektor usaha penggerak perekonomian karena usaha kecil menengah mampu menyerap tenaga kerja dan salah satu pelaku usaha yang mampu merasakan dampak dari globalisasi. Perusahaan yang memiliki banyak kelebihan dari usaha kecil menengah yang dapat dilihat dari segi teknologi, manajemen dan jaringan dari usaha kecil menengah dan sebagai berikut, menjadi ancaman yang kuat bagi Usaha Kecil Menengah di Sidoarjo. Hal tersebut menuntuk Usaha Kecil Menengah bersaing dalam segala bidang agar tetap bertahan di pasar dan dapat diterima oleh para konsumen. Dengan adanya kesadaran dari konsumen terhadap kualitas yang diharapkan maka menjadi suatu dorongan tersendiri bagi para pelaku usaha dalam hal bersaing menghasilkan produk (barang/jasa) yang berkualitas.

Kualitas yang sangat tinggi memungkinkan suatu usaha meningkat kepuasan bagi pelanggan, membuat produk habis terjual, bisa bersaing dengan para pesaing, dan meningkatkan pangsa pasar. Upaya peningkatan kualitas harus dilakukan secara menyeluruh dan terus menerus sesuai perkembangan selera konsumen. Hal ini disebabkan kriteria kualitas untuk setiap orang berbeda-beda baik dalam jenis maupun tingkat penggunaannya. Untuk memperoleh kualitas barang yang baik maka perlu adanya manajemen kualitas.

Alternatif yang dapat digunakan dalam meningkatkan daya saing produk UKM adalah dengan adanya standarisasi produk, dengan menerapkan standarisasi produk hasil UKM secara tidak langsung dapat melindungi konsumen dari kualitas produk yang digunakan. Untuk mengetahui indikator-indikator yang dapat digunakan dalam pengukuran kinerja UKM sehingga dapat meningkatkan daya saing produk UKM menggunakan metode Malcolm Baldridge National Quality Award (MBNQA). Terdapat tujuh kriteria dalam penerapan kriteria MBNQA yaitu: (1). Kepemimpinan, (2). Perencanaan Strategi, (3). Fokus kepada Pelanggan dan Pasar, (4). Pengukuran, Analisa, dan Manajemen pengetahuan, (5). Fokus Sumberdaya Manusia, (6). Manajemen Proses, dan (7). Hasil Bisnis (Gaspersz, 2007).

Untuk penelitian ini maka digunakan metode Structural Equation Modelling (SEM). Structural Equation Modelling (SEM) adalah suatu teknik statistika untuk menguji dan mengestimasi hubungan kausal dengan mengintegrasikan analisis faktor dan analisis jalur (Wright dalam Jogiyanto, 2011). Structural Equation Modelling (SEM) memiliki kemampuan 
mengukur variabel laten yang tidak secara langsung diukur tetapi melalui estimasi indikator atau parameternya. Hal tersebut memungkinkan peneliti melakukan pengujian secara eksplisit tingkat konsistensi alat ukur dan konsistensi internal (reliabilitas) suatu model penelitian yang secara teoritis hubungan struktural antar variabel laten dapat diestimasi secara akurat. Selain itu, SEM dapat melakukan analisa faktor, analisa jalur, dan regresi (Jogiyanto, 2011).

\section{METODE PENELITIAN}

\section{A. Tahap Pengumpulan Data}

Pada teknik pengumpulan data ini ada beberapa cara yang digunakan dalam penelitian ini adalah:

1. Interview (wawancara)

Yaitu suatu teknik pengumpulan data yang diperoleh dengan melakukan wawancara terhadap pemilik Usaha Kecil Menengah (UKM) di Kabupaten Sidoarjo.

2. Observasi (pengamatan)

Yaitu suatu pengumpulan data yang diperoleh dengan cara melakukan pengamatan dan pencatatan secara langsung pada obyek yang di teliti.

3. Angket atau Kuesioner

Yaitu metode pengambilan data yang berupa pertanyaan-pertanyaan tertulis yang diajukan kepada responden untuk mendapatkan jawaban. Skala pengukuran yang digunakan dalam penelitian ini adalah skala likers, yaitu skala yang secara luas digunakan untuk meminta responden menandai derajat persetujuan atau ketidaksetujuan terhadap serangkaian objek. Skala ini menggunakan poin skala dan derajat persetujuan sangat tidak baik sampai sangat baik. Didalam penelitian ini digunakan rentang 1 sampai 4, dimana nilai 1 dikategorikan ukuran penilaian sangat tidak baik (STB), nilai 2 tidak baik (TB), nilai 3 menunjukkan ukuran baik (B), dan nilai 4 menunjukkan ukuran sangat baik (SB).

Pada penelitian ini kuesioner diberikan kepada pelaku UKM (Usaha Kecil Menengah) yang ada di Kabupaten Sidoarjo. Syarat jumlah sampel dianjurkan bergantung pada jumlah indikator yang diteliti. Menurut Hair dkk (1998) dalam Wiyono (2013) menyebutkan bahwa jumlah sampel dapat dihitung dengan besarnya parameter dikali dengan 5 atau 10. Jadi pada penelitian ini jumlah sampel minimum 24 x $5=120$ dan jumlah maksimum $24 \times 10=240$.

\section{B. Indikator Penelitian}

Variabel laten yang terbentuk dalam kerangka teorotis penelitian masih belum dapat dikatakan sebagai variabel yang terukur sehingga membutuhkan variabel indikator sebagai dasar modal pengukurannya. Tabel 1 berikut ini menunjukkan variabel dan indikator penelitian yang menjadi bahan menyususn question research penelitian. 
Tabel 1. Indikator Penelitian

\begin{tabular}{|c|c|c|}
\hline Variabel & & Indikator \\
\hline \multirow[t]{3}{*}{ Kepemimpinan } & $\mathrm{X} 1.1$ & Peran Pimpinan Puncak \\
\hline & $\mathrm{X} 1.2$ & Tata kelola organisasi \\
\hline & $\mathrm{X} 1.3$ & Monitoring Kinerja \\
\hline \multirow[t]{3}{*}{ Perencanaan Strategi } & $\mathrm{X} 2.1$ & Pengembangan strategi \\
\hline & $\mathrm{X} 2.2$ & Pemberdayaan \\
\hline & $\mathrm{X} 2.3$ & Implementasi strategi \\
\hline \multirow[t]{2}{*}{ Fokus kepada Pelanggan } & $\begin{array}{l}\mathrm{X} 3.1 \\
\mathrm{X} 3.2\end{array}$ & $\begin{array}{l}\text { Pengetahun mengenai konsumen dan pasar } \\
\text { Kepuasan konsumen }\end{array}$ \\
\hline & $\mathrm{X} 3.3$ & Pengembangan budaya kualitas \\
\hline \multirow[t]{3}{*}{$\begin{array}{l}\text { Pengukuran, Analisa, dan } \\
\text { Manajemen Pengetahuan }\end{array}$} & $\mathrm{X} 4.1$ & $\begin{array}{l}\text { Pengukuran, analisa, dan peningkatan kinerja } \\
\text { organisasi }\end{array}$ \\
\hline & $\mathrm{X} 4.2$ & $\begin{array}{l}\text { Manajemen Informasi, Teknologi Informasi } \\
\text { dan Pengetahuan }\end{array}$ \\
\hline & $\mathrm{X} 4.3$ & Ketersediaan data atau informasi \\
\hline \multirow[t]{2}{*}{ Fokus Sumber Daya Manusia } & $\begin{array}{l}\mathrm{X} 5.1 \\
\mathrm{X} 5.2\end{array}$ & $\begin{array}{l}\text { Pemberdayaan karyawan } \\
\text { Pengembangan karyawan }\end{array}$ \\
\hline & $\mathrm{X} 5.3$ & Penilaian Karyawan \\
\hline \multirow[t]{3}{*}{ Manajemen Proses } & X6.1 & Sistem Kerja \\
\hline & X6.2 & Proses Kerja \\
\hline & X6.3 & Perencanaan operasional \\
\hline \multirow[t]{2}{*}{ Hasil Bisnis } & $\begin{array}{l}X 7.1 \\
X 7.2\end{array}$ & $\begin{array}{l}\text { Hasil produk dan layanan } \\
\text { Hasil fokus pelanggan }\end{array}$ \\
\hline & $\mathrm{X} 7.3$ & Hasil Keuangan dan pasar \\
\hline \multirow[t]{3}{*}{ Daya Saing } & Y1.1 & Kesiapan bersaing \\
\hline & Y1.2 & Permintaan Pasar \\
\hline & Y1.3 & Informasi Yang Luas \\
\hline
\end{tabular}

\section{Konseptual Penelitian}

Pada tahap konseptual ini menggambarkan dari konsep penelitian yang telah dilakukan dalam sebuah tabel. Hubungan variabel yang ditunjukkan di dapatkan hipotesa penelitian sebagai berikut:

Hipotesa 1 : Terdapat hubungan signifikan antara kepemimpinan dengan daya saing.

Hipotesa 2 : Terdapat hubungan signifikan antara perencanaan strategi dengan daya saing.

Hipotesa 3 : Terdapat hubungan signifikan antara fokus pasar dan pelanggan dengan daya saing.

Hipotesa 4 : Terdapat hubungan signifikan antara pengukuran, analisis dan manajemen pengetahuan dengan daya saing.

Hipotesa 5 : Terdapat hubungan signifikan antara fokus sumber daya manusia dengan daya saing.

Hipotesa 6 : Terdapat hubungan signifikan antara manajemen proses dengan daya saing. Hipotesa 7 : Terdapat hubungan signifikan antara hasil-hasil bisnis dengan daya saing. 


\section{HASIL DAN PEMBAHASAN}

\section{A. Gambaran Umum}

Responden pada penelitian ini adalah pelaku Usaha Kecil Menengah (UKM) yang berapa di Kabupaten Sidoarjo, dengan jumlah responden 120 Usaha Kecil Menengah. Menurut Hair dkk (1998) dalam Wiyono (2013) pengambilan sampel dapat dihitung dengan besarnya parameter dikali dengan 5 sampai dengan 10. Pada penelitian ini jumlah sampel yang digunakan adalah sesuai dengan jumlah indikator 24 x $5=120$ orang. Dengan penyebaran kuesioner yang dilakukan di sentra UKM tas yang berada di selatan Kabupaten Sidoarjo, sentra UKM topi yang berada di utara Kabupaten Sidoarjo, sentra UKM telor asin berada di timur Kabupaten Sidoarjo, dan sentra UKM krupuk berada di barat Kabupaten Sidoarjo diharapkan dapat mewakili seluruh populasi Usaha Kecil Menengah yang ada di Kabupaten Sidoarjo.

\section{B. Uji Validitas}

Menurut Sujarweni (2015) uji validitas digunakan untuk mengetahui kelayakan butirbutir dalam suatu daftar pertanyaan dalam mendefinisikan suatu variabel. Uji validitas sebaiknya dilakukan pada setiap butir pertanyaan divaliditasnya. Hasil $r$ hitung dibandingkan dengan $\mathrm{r}$ tabel dimana $\mathrm{df}=\mathrm{n}-2$ dengan sig $5 \%$. Jika $\mathrm{r}$ tabel $<\mathrm{r}$ hitung maka valid.

Tabel 2. Hasil Uji Validitas

\begin{tabular}{|c|c|c|c|c|}
\hline \multicolumn{2}{|l|}{ Variabel } & \multirow{2}{*}{$\begin{array}{l}\text { Indikator } \\
\text { Peran Pimpinan Puncak }\end{array}$} & \multirow{2}{*}{$\begin{array}{c}\text { R } \\
\text { Hitung } \\
0.741\end{array}$} & \multirow{2}{*}{$\frac{\text { Keterangan }}{\text { Valid }}$} \\
\hline Kepemimpinan & $\mathrm{X} 1.1$ & & & \\
\hline & $\mathrm{X} 1.2$ & Tata kelola organisasi & 0.648 & Valid \\
\hline & $\mathrm{X} 1.3$ & Monitoring Kinerja & 0.515 & Valid \\
\hline \multirow{3}{*}{$\begin{array}{l}\text { Perencanaan } \\
\text { Strategi }\end{array}$} & $\mathrm{X} 2.1$ & Pengembangan strategi & 0.429 & Valid \\
\hline & $\mathrm{X} 2.2$ & Pemberdayaan & 0.559 & Valid \\
\hline & $\mathrm{X} 2.3$ & Implementasi strategi & 0.521 & Valid \\
\hline \multirow[t]{3}{*}{$\begin{array}{l}\text { Fokus kepada } \\
\text { Pelanggan }\end{array}$} & $\mathrm{X} 3.1$ & $\begin{array}{l}\text { Pengetahun mengenai konsumen } \\
\text { dan pasar }\end{array}$ & 0.421 & Valid \\
\hline & $\mathrm{X} 3.2$ & Kepuasan konsumen & 0.352 & Valid \\
\hline & $\mathrm{X} 3.3$ & Pengembangan budaya kualitas & 0.387 & Valid \\
\hline \multirow{3}{*}{$\begin{array}{l}\text { Pengukuran, } \\
\text { Analisa, dan } \\
\text { Manajemen } \\
\text { Pengetahuan }\end{array}$} & $\mathrm{X} 4.1$ & $\begin{array}{l}\text { Pengukuran, analisa, dan } \\
\text { peningkatan kinerja organisasi }\end{array}$ & 0.545 & Valid \\
\hline & $\mathrm{X} 4.2$ & $\begin{array}{l}\text { Manajemen Informasi, } \\
\text { Teknologi Informasi dan } \\
\text { Pengetahuan }\end{array}$ & 0.512 & Valid \\
\hline & $\mathrm{X} 4.3$ & Ketersediaan data atau informasi & 0.578 & Valid \\
\hline Fokus Sumber & $\mathrm{X} 5.1$ & Pemberdayaan karyawan & 0.581 & Valid \\
\hline \multirow[t]{2}{*}{ Daya Manusia } & $\mathrm{X} 5.2$ & Pengembangan karyawan & 0.372 & Valid \\
\hline & $\mathrm{X} 5.3$ & Penilaian Karyawan & 0.543 & Valid \\
\hline Manajemen & X6.1 & Sistem Kerja & 0.653 & Valid \\
\hline \multirow[t]{2}{*}{ Proses } & X6.2 & Proses Kerja & 0.571 & Valid \\
\hline & X6.3 & Perencanaan operasional & 0.648 & Valid \\
\hline \multirow[t]{3}{*}{ Hasil Bisnis } & $\mathrm{X} 7.1$ & Hasil produk dan layanan & 0.355 & Valid \\
\hline & $\mathrm{X} 7.2$ & Hasil fokus pelanggan & 0.361 & Valid \\
\hline & $\mathrm{X} 7.3$ & Hasil Keuangan dan pasar & 0.237 & Valid \\
\hline \multirow[t]{3}{*}{ Daya Saing } & Y1.1 & Kesiapan bersaing & 0.366 & Valid \\
\hline & Y1.2 & Permintaan Pasar & 0.279 & Valid \\
\hline & Y1.3 & Informasi Yang Luas & 0.213 & Valid \\
\hline
\end{tabular}


Data yang diuji adalah data sebanyak 120 responden dengan menggunakan aplikasi komputer SPSS 16.0. Dengan responden sebanyak 120 didapatkan $r$ tabel sebesar 1,66. Jika nilai corrected item-total correlation diatas 1,66 maka data tersebut dapat dikatakan valid.

\section{Uji Reliabilitas}

Menurut Sujarweni (2015) Uji reliabilitas (keandalan) merupakan ukuran suatu kestabilan dan konsistensi responden dalam menjawab hal yang berkaitan dengan kontruk-kontruk pertanyaan yang merupakan dimensi suatu variabel dan disusun dalam suatu bentuk kuisioner. Uji reliabilitas dapat dilakukan secara bersama-sama terhadap seluruh butir pertanyaan. Jika nilai Cronbach's Alpha > 0,60 maka reliabel.

Tabel 3. Hasil Uji Reliabilitas

\begin{tabular}{cc}
\hline Cronbach's Alpha & Keterangan \\
\hline 0,894 & Reliabel \\
\hline
\end{tabular}

\section{Pengujian Struktural Model}

Uji Struktural Model ini untuk mengetahui hubungan antar konstruk yang mempunyai hubungan causal atau sebab akibat (Santoso 2012). Dengan melakukan uji struktural model dapat diketahui apakah model keseluruhan sudah fit pada setiap variabel eksogen dan endogen, jika ada yang tidak fit maka akan dimodifikasi sampai model menjadi fit.

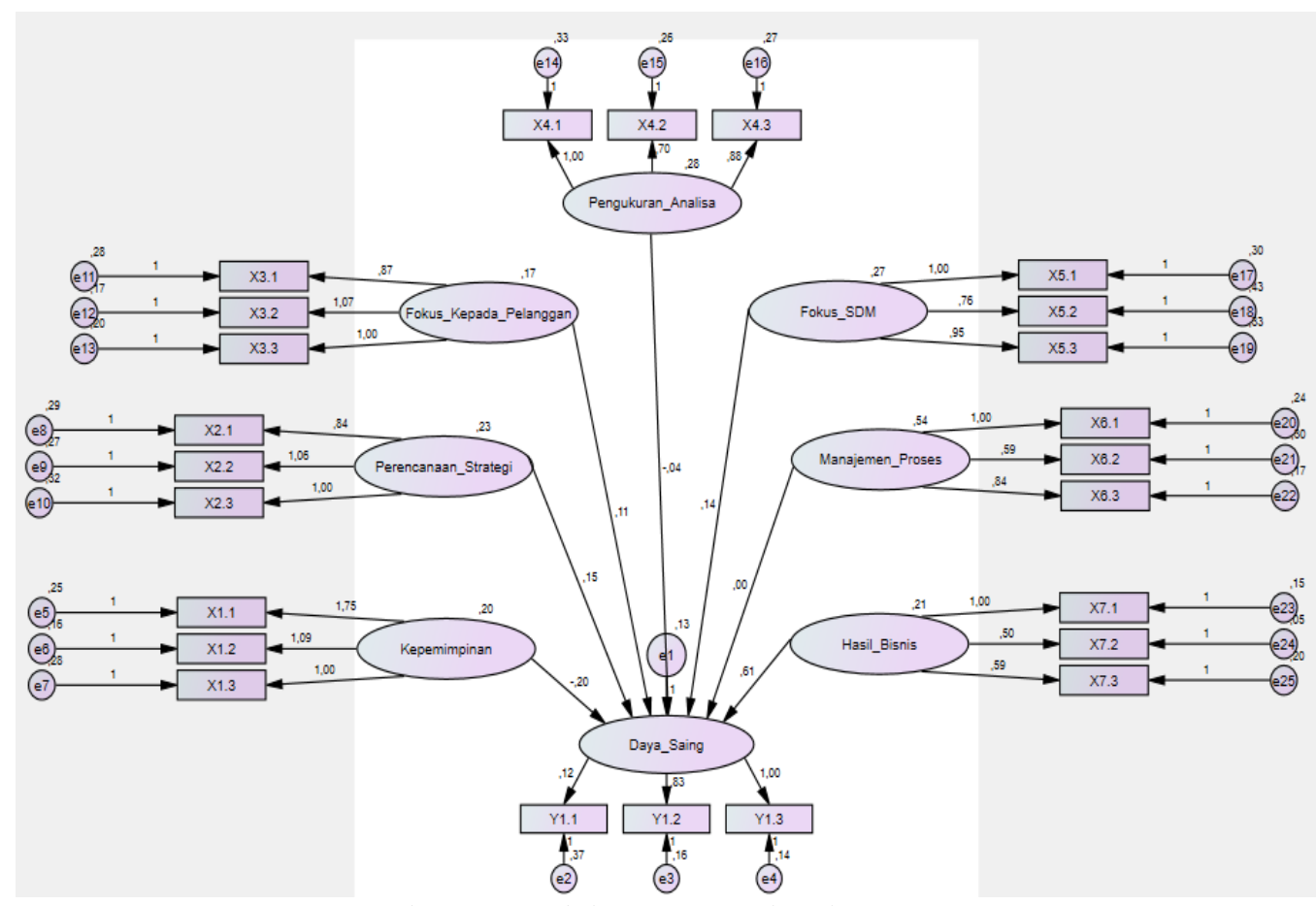

Gambar 1. Model SEM Keseluruhan

Dari hasil yang ditunjukkan pada gambar 1 memberikan keterangan nilai Goodness $O f$ Index (GFI) sebesar 0,595, Comparative Fit Index (CFI) sebesar 0,380, Normo Fit Index (NFI) sebesar 0,338 dan juga didapatkan keterangan nilai CR sebesar -1,730, P sebesar 0,084 , dan $\mathrm{T}$ sebesar $-0,201$. Untuk model yang dikatakan fit harus salah satu dari parameter memiliki nilai 0,9 atau mendekati 1 (Santoso 2012). Tapi pada model ini tidak 
ada satu pun nilai yang diatas 0,9 atau mendekati 1 maka model tidak fit dan perlu untuk dimodifikasi.

\section{E. Modifikasi Model}

Proses modifikasi sebuah model pada dasarnya sama dengan mengulang proses pengujian dan estimasi model. Hanya disini ada proses tambahan untuk mengidentifikasi variabel mana yang akan diolah lebih lanjut. Untuk memodifikasi model menggunkan rekomendasi yang dihasilkan oleh software AMOS 21 terdapat pada pada menu output yang bernama modification inside. Pada output tersebut menunjukkan variabel-variabel yang perlu untuk dimodifikasi agar model menjadi fit. Berikut dapat dilihat hasil modifikasi model pada gambar 2 .

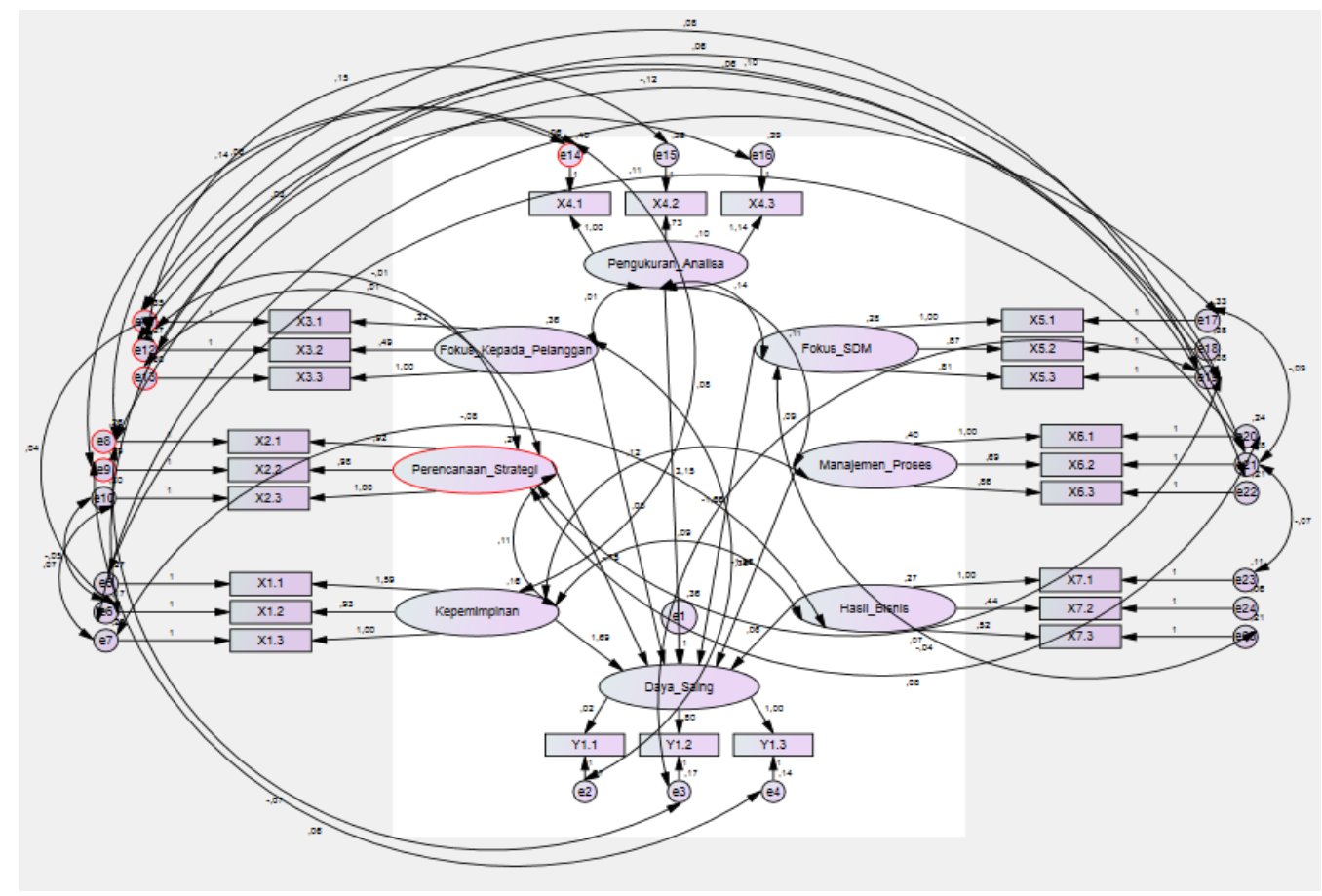

Gambar 2. Model SEM Modifikasi

Hasil dari uji structural model yang telah dimodifikasi pada gambar 2 memberikan keterangan model dinyatakan fit karena ada parameter yang telah memenuhi nilai standar dengan nilai 0,9 atau mendekati 1 diantaranya terdapat pada parameter Comparative Fit Index (CFI) dengan nilai 0,907.

\section{F. Pengujian Hipotesa}

Setelah semua model sudah pastikan fit maka langkah selanjutnya adalah menguji kausalitas yakni menguji apakah antar variabel sesuai dengan hipotesa. Parameter ada tidaknya pengaruh secara parsial dapat diketahui berdasarkan nilai CR (Critical Rasio), P (Probability), t-value. 
Tabel 4. Hasil Pengujian Hipotesa

\begin{tabular}{|c|c|c|c|c|}
\hline \multirow{2}{*}{ Hipotesa } & \multirow{2}{*}{ Hubungan } & \multicolumn{2}{|c|}{$\begin{array}{c}\text { Nilai CR, Probabilitas, } \\
\text { dan t-value }\end{array}$} & \multirow[t]{2}{*}{ Keterangan } \\
\hline & & Standar & Hasil Output & \\
\hline $\mathrm{H} 1$ & $\begin{array}{l}\text { Kepemimpinan } \\
\text { berpengaruh terhadap } \\
\text { daya saing }\end{array}$ & $\begin{array}{l}\mathrm{CR}>1,96 \\
\mathrm{P}<0,05 \\
\mathrm{~T}>0,5\end{array}$ & $\begin{array}{l}C R>3,521 \\
P<0,000 \\
T>1,570\end{array}$ & Signifikan \\
\hline $\mathrm{H} 2$ & $\begin{array}{lr}\text { Perencanaan } & \text { Strategi } \\
\text { berpengaruh } & \text { terhadap } \\
\text { daya saing } & \end{array}$ & $\begin{array}{l}\mathrm{CR}>1,96 \\
\mathrm{P}<0,05 \\
\mathrm{~T}>0,5\end{array}$ & $\begin{array}{l}\mathrm{CR}>-3,308 \\
\mathrm{P}<0,000 \\
\mathrm{~T}>-0,751\end{array}$ & Signifikan \\
\hline $\mathrm{H} 3$ & $\begin{array}{l}\text { Fokus kepada } \\
\text { pelanggan berpengaruh } \\
\text { terhadap daya saing }\end{array}$ & $\begin{array}{l}\mathrm{CR}>1,96 \\
\mathrm{P}<0,05 \\
\mathrm{~T}>0,5\end{array}$ & $\begin{array}{l}C R>0,807 \\
P<0,419 \\
T>0,053\end{array}$ & $\begin{array}{c}\text { Tidak } \\
\text { Signifikan }\end{array}$ \\
\hline $\mathrm{H} 4$ & $\begin{array}{l}\text { Pengukuran, analisa, } \\
\text { dan manajemen } \\
\text { pengetahuan } \\
\text { berpengaruh terhadap } \\
\text { daya saing }\end{array}$ & $\begin{array}{l}\mathrm{CR}>1,96 \\
\mathrm{P}<0,05 \\
\mathrm{~T}>0,5\end{array}$ & $\begin{array}{l}C R>2,432 \\
P<0,015 \\
T>3,147\end{array}$ & Signifikan \\
\hline H5 & $\begin{array}{l}\text { Fokus sumber daya } \\
\text { manusia berpengaryh } \\
\text { terhadap daya saing }\end{array}$ & $\begin{array}{l}\mathrm{CR}>1,96 \\
\mathrm{P}<0,05 \\
\mathrm{~T}>0,5\end{array}$ & $\begin{array}{l}C R>-2,500 \\
P<0,012 \\
T>-1,656\end{array}$ & Signifikan \\
\hline H6 & $\begin{array}{lr}\text { Manajemen } & \text { proses } \\
\text { berpengaruh } & \text { terhadap } \\
\text { daya saing } & \end{array}$ & $\begin{array}{l}C R>1,96 \\
P<0,05 \\
T>0,5\end{array}$ & $\begin{array}{l}C R>-3,207 \\
P<0,001 \\
T>-1,356\end{array}$ & Signifikan \\
\hline $\mathrm{H} 7$ & $\begin{array}{lr}\text { Hasil } & \text { bisnis } \\
\text { berpengaruh } & \text { terhadap } \\
\text { daya saing } & \end{array}$ & $\begin{array}{l}\mathrm{CR}>1,96 \\
\mathrm{P}<0,05 \\
\mathrm{~T}>0,5\end{array}$ & $\begin{array}{l}\mathrm{CR}=0,332 \\
\mathrm{P}=0,747 \\
\mathrm{~T}=0,059\end{array}$ & $\begin{array}{c}\text { Tidak } \\
\text { Signifikan }\end{array}$ \\
\hline
\end{tabular}

\section{G. Usulan dari Hasil Penelitian}

Berdasarkan hasil dari penelitian yang telah dilakukan terdapat beberapa saran yang ditujukan kepada para pelaku UKM (Usaka Kecil Menengah) yang berhubungan dengan daya saing produk UKM yang disebabkan oleh beberapa faktor.

1. Untuk variabel kepemimpinan indikator pembentuk terlemah adalah monitoring kinerja yang berarti pemimpin harus lebih teliti dan lebih baik lagi dalam mereview kinerja dan hasil usaha, sehingga dalam penetapan hal-hal yang akan dilaksanakan ke depannya bisa lebih baik dan sukses sesuai dengan target pencapaian yang diharapkan oleh UKM sesuai dengan kebijakan dan aturan yang berlaku dan sudah menjadi ketetapan semestinya (Utami 2014).

2. Untuk variabel perencanaan strategi indikator pembentuk terlemah adalah pengembangan strategi yang menunjukkan bahwa pengembangan strategi yang ditetapkan pada UKM kurang baik sehingga perlu adanya evaluasi dan perbaikan. Misalnya untuk kedepanya pelaku UKM merancang strategi jangka pendek, jangka menengah, dan jangka panjang yang bertujuan supaya dapat diukur tercapaian tujuan dan strategi yang telah direncanakan sehingga pengembangan strategi dapat diketahui dan motivasi kepada karyawan untuk menyumbangkan ide dan inovasi perlu ditingkatkan yaitu dengan memberikan penghargaan kepada karyawan yang 
memberikan ide dan inovasi terbaik dan membawa kemajuan organisasi (Arnenda 2014).

3. Untuk variabel pengukuran, analisa dan manajemen pengetahuan indikator pembentuk variabel terlemah adalah manajemen informasi, teknologi informasi dan pengetahuan yang menunjukkan penerapan manajemen informasi, teknologi informasi dan pengetahuan pada UKM berjalan kurang baik sehingga perlu adanya evaluasi dan perbaikan. UKM diharapkan menerapkan strategi yang dapat dilakukan untuk menghadapi ancaman persaingan khusus antara UKM yang ada di Kabupaten Sidoarjo yang semakin hari lebih meningkat adalah dengan mengaktifkan sosial media agar supaya dapat meningkatkan proses pemasaran yang lebih efisien dan murah (Lang 2015).

4. Untuk variabel fokus sumber daya manusia indikator pembentuk terlemah adalah pengembangan karyawan yang menunjukkan bahwa UKM memerlukan sumber daya manusia yang memiliki kapabilitas di bidangnya sehingga mampu mendukung perkembangan UKM di Kabupaten Sidoarjo (Kurniawan 2014). Pengembangan karyawan yang diterapkan pada UKM kurang baik dan perlu adanya pengukuran kinerja sehingga karyawan yang kurang dalam ilmu pengetahuan dan keterampilan diberi suatu pelatihan dan selaku pimpinan UKM selalu melakukan peninjauan berdasarkan target pencapaian, output yang dihasilkan dari karyawan.

5. Untuk variabel manajemen proses indikator pembentuk terlemah adalah perencanaan operasional yang menunjukkan bahwa UKM diharapkan dalam melakukan perencanaan operasional maka diperlukan langkah-langkah tertentu, langkah-langkah tersebut merupakan prosedur yang harus di ikuti dalam setiap melakukan perencanaan, sebab tanpa prosedur maka kurang sempurna perencanaan tersebut. Langkah langkah tersebut yaitu menetapkan tujuan, memahami atau merumuskan keadaan saat ini dan mengidentifikasi kemudahan dan hambatan.

\section{SIMPULAN}

Kesimpulan yang dapat ditarik dari hasil penelitian adalah:

1. Terdapat hubungan positif antara kepemimpinan dengan daya saing produk UKM.

2. Terdapat hubungan signifikasn antara perencanaan strategi dengan daya saing produk UKM.

3. Tidak terdapat hubungan signifikan antara fokus kepada pelanggan dengan daya saing produk UKM.

4. Terdapat hubungan signifikasn antara pengukuran, analisa, dan manajemen pengetahuan dengan daya saing produk UKM.

5. Terdapat hubungan signifikan antara fokus sumber daya manusia dengan daya saing produk UKM.

6. Terdapat hubungan signifikan antara manajemen proses dengan daya saing produk UKM.

7. Tidak terdapat hubungan signifikan antara hasil-hasil bisnis dengan dayan saing produk UKM. 


\section{DAFTAR PUSTAKA}

Arnenda, Rizki (2014). Identifikasi Pencapaian Kinerja Perusahaan PT. Pindad (Persero) dengan Menggunakan Metode Malcolm Baldrige, Jurnal Kalibrasi Sekolah Tinggi Teknologi Garut, Vol. 12 No. 1

Fakultas, Marno Nogroho, (2015). Model Peningkatan Kinerja Operasional melalui Praktekpraktek Manajemen Kualitas Pada Industri Kecil Menengah (IKM) di Kota Semarang, Jurnal World Class Islamic University, Vol. 2 No. 1

Gaspersz, Vincent, (2007). Ge Way Malcolm Baldrige Criteria For Performance Excellence, Jakarta: PT Gramedia Pustaka Utama.

Jogiyanto, (2011). Konsep dan Aplikasi Structural Equation Modeling Berbasis Varian dalam Penelitian Bisnis, Yogyakarta: Unit Penerbit dan Percetakan STIM YKPN.

Kurniawan, Asep, (2014). Manajemen Kualitas Pada Usaha Kecil dan Menengah (UKM) Di Jawa Barat, Portofolio, Volume 11 No. 1, hal. 77 -93.

Lang, Kana, (2015). Strategi Menciptakan Daya Saing Nilai Produk Usaha Mikro Di Manado (Studi Kasus UD. Kloeman Bakery), Jurnal Berkala Ilmiah Efisiensi, Volume 15 No. 05

Santoso, Singgih, (2012). Analisis SEM Menggunakan AMOS, Jakarta: PT Alex Media Komputindo.

Sujarweni, V Wiratna, (2015). Statistik Untuk Bisnis dan Ekonomi, Yogyakarta: Pustaka Baru Press.

Utami, Putri, (2014). Analisis Pengaruh Enam Kriteria Lainnya Dalam Malcolm Baldrige Criteria For Performance Excellence (MBCFPE) Terhadap Kepemimpinan Pada PT. Krakatau Steel (Persero) Tbk, e-Proceeding of Management Vol.1, No.3.

Wiyono, Karsono, Dewi, Amina Sukma, (2013), Analisis Anteseden Orientasi Pasar dan Pengaruhnya Terhadap Pembelejaran Organisasi UMKM di Eks Karesidenan Surakarta, Semnas Fekon, Optimisme Ekonomi Indonesia 2013, Hal 3. 
